\title{
Use of Wigglesworth pathophysiological classification for perinatal mortality in Malaysia
}

\author{
H S S Amar, Abdul Hamid Maimunah, Swee Lan Wong
}

\begin{abstract}
A one year prospective study of perinatal deaths was conducted to test the feasibility of using the Wigglesworth pathophysiological classification in the Malaysian health service. Four regions with high perinatal mortality rates were selected. Deaths were actively identified. Nursing staff were trained to use the classification and every death was reviewed by a clinician.
\end{abstract}

A total of 26198 births and 482 perinatal deaths were reported. The perinatal mortality rate was $18 \cdot 4$. Only $14(2 \cdot 9 \%)$ deaths had their Wigglesworth category reclassified. Most deaths were in the normally formed macerated stillbirths (34.4\%), asphyxial conditions $(26 \cdot 8 \%)$, and immaturity $(20 \cdot 1 \%)$ subgroups. The results were compared with data from other countries that used this classification.

This study has shown that the Wigglesworth pathophysiological classification can be applied to perinatal deaths in the existing Malaysian health service. (Arch Dis Child 1996; 74: F56-F59)

Keywords: Wigglesworth pathophysiological classification, perinatal mortality, Malaysia.

There has been a progressive reduction in perinatal mortality in Malaysia from 38.9 in 1967 to 26.7 in 1980 and 13.9 in $1990 .^{1}$ This decline, however, has not been as rapid as the drop in postnatal mortality over the same period. Perinatal mortality is also high compared with that in developed countries. Furthermore, perinatal mortality varies widely among different regions in the country.

The perinatal mortality rate of a country is often used as a measure of the adequacy of obstetric and neonatal services. It is, however, increasingly recognised that many factors determine perinatal outcome. This has made analysis of perinatal data difficult and limited the evaluation of any intervention. Various attempts have been made locally to examine the problem and to suggest recommendations for the improvement of perinatal care. ${ }^{2-4}$

Any attempt to analyse perinatal mortality data usually faces the problem of selecting or developing a classification system for the cause of death. Classification systems vary with the specialty of the individual who proposes them. Several classification systems have been proposed by obstetricians, neonatologists/paediatricians, perinatal pathologists and epidemiologists. ${ }^{5-10}$ Each classification has its strengths and weaknesses. When selecting a classification system it is important to understand the aims. The aim of any classification of perinatal deaths should be to derive strategies for the prevention of perinatal mortality. ${ }^{59}$ Obstetric classifications concentrate on maternal factors and take little account of the fetal/neonatal clinicopathological process. ${ }^{6}$ Pathological classifications depend heavily on the availability of necropsies which are extremely difficult to obtain in Malaysia because of cultural and religious beliefs.

The Wigglesworth pathophysiological approach $^{59}$ to the classification of perinatal deaths is appealing because it is simple, reproducible, and can be used without a necropsy. A preliminary study was conducted in two regions in Malaysia using this approach in 1988. ${ }^{11}$ The study was hampered, however, by its retrospective nature which limited the availability of information for accurate and reliable classification of perinatal deaths.

With this in mind, a one year prospective study of perinatal mortality was conducted. This study looked at strengthening notification of perinatal deaths, use of the Wigglesworth classification by staff at ground level, and an in-depth analysis of selected perinatal deaths. It was hoped that this study would help develop a system which could be implemented nationwide.

\section{Method}

A prospective, descriptive study was conducted from November 1990 to October 1991 in four selected regions in Malaysia. Three of the regions were districts from Peninsular Malaysia and the fourth was a division (comprising four districts) from East Malaysia. These regions were selected on the basis of having high reported perinatal mortality rates when compared with the national average and the presence of public health physicians or clinicians interested in perinatal mortality research. These regions are predominantly rural and semi-urban, and as such, maternal and child health services are largely provided by the government health facilities.

The study used the definition of perinatal deaths as stillbirths with a gestation period of 28 weeks or more and live births who survive for less than 7 days (less than 168 hours). For stillbirths with uncertain or unknown period of gestation, fetuses weighing $500 \mathrm{~g}$ or more were accepted into the study. Although this definition differed from that suggested by the World Health Organisation (WHO), ${ }^{12}$ in using 28 weeks and not 22 weeks as the cutoff gestational age for stillbirths, there was general 
consensus among clinicians that this would be the more appropriate definition for the current situation in Malaysia.

Only perinatal deaths occurring to mothers who had been resident in the study regions for at least six months of the pregnancy were accepted. This was done for two reasons. First, it is a recognition of the impact of antenatal care on perinatal outcome. Secondly, in view of the high geographical mobility of Malaysian mothers at the time of delivery, assignment of perinatal deaths to the region where antenatal care was obtained is a better reflection of services provided.

An active enquiry system was adopted to identify perinatal deaths. This included regular visits to private maternity homes, police stations, and heads of villages. Home visits were conducted for more rural settings. Every pregnancy registered with the government health service was followed up to determine its outcome. Perinatal deaths occurring in areas outside the study regions, but receiving antenatal care in the study regions, were identified by collaboration with the health departments of neighbouring areas.

Formats were developed to help in the notification and classification of perinatal deaths. These included a flow chart for classifying deaths according to Wigglesworth's pathophysiological classification (figure). Public health sisters, public health nurses, and staff nurses from both hospital and health facilities in the study regions were trained in the use of these formats. All available records for each perinatal death, both maternal and neonatal, together with the completed formats were made available to obstetricians and paediatricians of the region. They actively participated by reviewing each perinatal death and commented on the classification of death, as well as the quality of management provided for each case. A detailed protocol was then used for the investigation of perinatal deaths in selected Wigglesworth categories. The results of this in-depth analysis are presented in a separate report for local use.

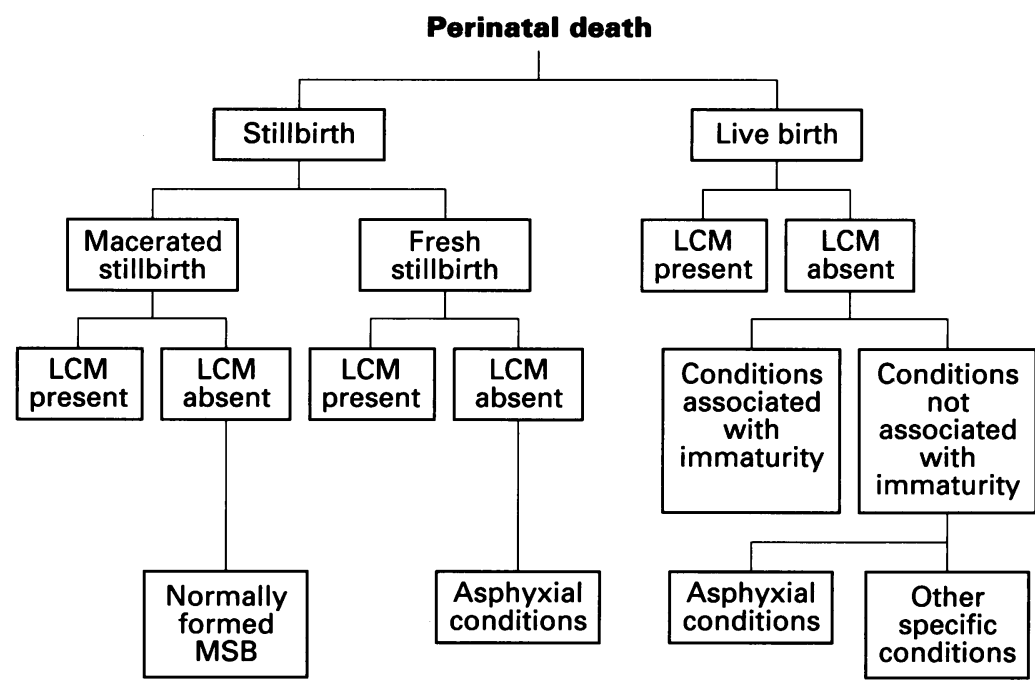

Flow Chart of the pathophysiological classification of perinatal deaths adopted from the Wigglesworth Approach. 5 MSB = Macerated stillbirth; LCM = Lethal congenital malformation; Other specific conditions example: kernicterus, haemorrhagic disease of the newborn, septicaemia.
This paper reports pooled data from all four regions and is confined to the use of the Wigglesworth pathophysiological classification.

\section{Results}

During the study period 24863 pregnancies were registered with the government health services. The outcomes of $94 \cdot 2 \%$ of these pregnancies were known. Of those unknown, 5\% were mothers who left the study regions before delivery and another $0.8 \%$ were those who had returned to villages within the study regions for delivery but were lost to follow up. A total of 26198 births and 482 perinatal deaths were reported during the study period. Of the perinatal deaths, $298(61 \cdot 8 \%)$ were stillborn and $184(38 \cdot 2 \%)$ were live births. The ratio of stillbirths to early neonatal deaths was $1 \cdot 6: 1$.

Of the stillborn, $178(59 \cdot 7 \%)$ were macerated stillbirths and $120(40.3 \%)$ fresh stillbirths. Of the stillbirths, $76 \cdot 1 \%$ were delivered in government hospital labour rooms, $21.5 \%$ at home, and $2.4 \%$ at other locations. Of the live births $54.9 \%$ died in the special care nurseries of government hospitals $-23.9 \%$ in some other government health facility, $11.4 \%$ at home, and $4.9 \%$ during transportation. Only three deaths were reported from private hospitals. More than half $(52 \cdot 2 \%)$ of the live births survived less than 24 hours and $70 \cdot 1 \%$ less than 48 hours.

In this study the birthweight of $97 \cdot 3 \%$ of the perinatal deaths could be ascertained, even though $36.9 \%$ were macerated stillbirths. The 13 deaths whose birthweights were not known were all stillbirths, seven of whom were macerated and were delivered by untrained personnel. The mean birthweight of the 469 deaths with known birthweight was $2034.2 \mathrm{~g}$, with a standard deviation of $936 \mathrm{~g}$, and a median of $2000 \mathrm{~g}$.

The overall perinatal mortality rate computed for the one year period in the four study regions was 18.40 per 1000 births. The overall stillbirth rate, 11.37 per 1000 births, made up a significantly higher proportion of the perinatal mortality rate.

Table 1 shows the 482 perinatal deaths grouped according to the pathophysiological classification and birthweight, as proposed by Wigglesworth. ${ }^{5}$ Only $14(2.9 \%)$ perinatal deaths had their pathophysiological category reclassified by obstetricians or paediatricians. These included changes that involved reclassification from various categories into the lethal congenital malformations category (six deaths) and reclassification from the immaturity category into other specific conditions (five deaths).

Using the Wigglesworth classification, it is clear that $81.3 \%$ of the deaths were in the groups comprising normally formed macerated stillbirths $(34.4 \%)$, asphyxial conditions $(26.8 \%)$, and conditions associated with immaturity $(20 \cdot 1 \%)$.

Of the perinatal deaths determined to have lethal congenital malformations, 12 were macerated stillbirths, 19 fresh stillbirths, and 35 live births. The most common identifiable 
Table 1 Perinatal deaths grouped according to the pathophysiological classification proposed by Wigglesworth

\begin{tabular}{|c|c|c|c|c|c|c|}
\hline Birthweight & $\begin{array}{l}\text { Normally formed } \\
\text { macerated } \\
\text { stillbirths }\end{array}$ & $\begin{array}{l}\text { Lethal } \\
\text { congenital } \\
\text { malformations }\end{array}$ & $\begin{array}{l}\text { Conditions } \\
\text { associated with } \\
\text { immaturity }\end{array}$ & $\begin{array}{l}\text { Asphyxial } \\
\text { conditions }\end{array}$ & $\begin{array}{l}\text { Other } \\
\text { specific } \\
\text { conditions }\end{array}$ & Total \\
\hline $\begin{array}{l}\text { Less than } 1001 \mathrm{~g} \\
1001-1500 \mathrm{~g} \\
1501-2000 \mathrm{~g} \\
2001-2500 \mathrm{~g} \\
\text { More than } 2500 \mathrm{~g} \\
\text { Unknown weight* }\end{array}$ & $\begin{array}{r}33 \\
35 \\
27 \\
21 \\
43 \\
7\end{array}$ & $\begin{array}{r}8 \\
10 \\
11 \\
16 \\
21 \\
0\end{array}$ & $\begin{array}{l}25 \\
37 \\
20 \\
15\end{array}$ & $\begin{array}{r}8 \\
11 \\
9 \\
27 \\
68 \\
6\end{array}$ & $\begin{array}{r}0 \\
1 \\
1 \\
2 \\
20\end{array}$ & $\begin{array}{c}74(15 \cdot 4 \%) \\
94(19 \cdot 5 \%) \\
68(14 \cdot 1 \%) \\
81(16 \cdot 8 \%) \\
152(31 \cdot 5 \%) \\
13(2 \cdot 7 \%)\end{array}$ \\
\hline Total & $166(34 \cdot 4 \%)$ & $66(13 \cdot 7 \%)$ & $97(20 \cdot 1 \%)$ & $129(26 \cdot 8 \%)$ & $24(5 \cdot 0 \%)$ & $482(100 \%)$ \\
\hline
\end{tabular}

^Modification to Wigglesworth table with an added 'unknown weight' categories was made as the stillbirths conducted by

untrained personnel are usually not weighed.

malformations detected were neural tube defects (18 anencephaly, two large meningomyelocoele). Four live births were determined to have died from complex congenital heart diseases. Neural tube defects or complex congenital heart disease, when occurring with multiple other abnormalities, were grouped under 'multiple congenital abnormalities'. Forty two deaths were due to multiple congenital abnormalities (seven of whom were hydrops fetalis, four had associated hydrocephalus, and two associated congenital heart disease).

Of the 24 perinatal deaths classified under other specific conditions, nine were attributable to septicaemia (seven confirmed, two presumed sepsis). Seven of these nine babies weighed more than $2500 \mathrm{~g}$. Three babies died from haemorrhagic disease of the newborn (two certain, one probable), one died from epidermolysis bullosa lethalis, and another from disseminated intravascular coagulation associated with subaponeurotic haemorrhage. In 10 cases the cause of death was unknown (seven of whom died at home).

\section{Discussion}

This study shows the Wigglesworth pathophysiological classification can be applied to perinatal deaths in the existing structure of the Malaysian health service. This study has found many advantages in using this classification. Its simplicity allowed nurses, once trained, to use the classification with little difficulty, making adoption on a national scale feasible. There was good agreement in the Wigglesworth classification between nurses and obstetricians or paediatricians as only $2.9 \%$ of perinatal deaths were reclassified.

The classification provides birthweight related data by pathophysiological subgroups, and these were useful for audit of perinatal services at a macro level. For example, the large number of deaths caused by asphyxial conditions, especially with birthweight of more than $2500 \mathrm{~g}$, as found in this study, indicates that prepartum care and neonatal resuscitation services need to be improved. ${ }^{5}$ The sizeable numbers of deaths as a result of macerated stillbirths in this study has implications for the quality and adequacy of antenatal care. It also reflects the socioeconomic status of the regions. ${ }^{5}$ Finally, perinatal deaths could be classified without the widespread availability of necropsies. Although this underestimates the number of deaths caused by lethal congenital malformations, ${ }^{9}$ it has enabled us to provide the first local community based data on perinatal deaths from lethal congenital malformations.

Use of the Wigglesworth pathophysiological classification has wider applications. It allows for the comparison of perinatal mortality data between countries adopting this method and provides more information than the perinatal mortality rate alone. An attempt to compare perinatal mortality data from this study with data from other countries using Wigglesworth pathophysiological classifications ${ }^{513-15}$ is presented in table 2 .

It is, however, important to note that comparison of data among different countries is limited by the year in which the data were collected, the source of data (community vs hospital based), the definition used for perinatal deaths and the availability of necropsies. Despite these limitations, it is evident from the comparison of the six studies that as the country in question is economically more developed, the percentage of normally formed macerated stillbirths decreases and that of lethal congenital malformations and conditions associated with immaturity rises. The

Table 2 Comparison of perinatal mortality data in countries using Wigglesworth pathophysiological classification

\begin{tabular}{|c|c|c|c|c|c|c|c|c|}
\hline \multirow[b]{2}{*}{ Country ${ }^{\star}$} & \multirow[b]{2}{*}{$\begin{array}{l}\text { Date of } \\
\text { study }\end{array}$} & \multirow[b]{2}{*}{ Sample origin } & \multicolumn{6}{|c|}{ Wigglesworth pathophysiological group } \\
\hline & & & $\begin{array}{l}\text { Normally } \\
\text { formed } \\
\text { macerated } \\
\text { stillbirths }\end{array}$ & $\begin{array}{l}\text { Lethal } \\
\text { congenital } \\
\text { malformations }\end{array}$ & $\begin{array}{l}\text { Conditions } \\
\text { associated } \\
\text { with } \\
\text { immaturity }\end{array}$ & $\begin{array}{l}\text { Asphyxial } \\
\text { conditions }\end{array}$ & $\begin{array}{l}\text { Other } \\
\text { specific } \\
\text { conditions }\end{array}$ & Total \\
\hline $\begin{array}{l}\text { Australia } \\
\text { (Victoria) }^{13}\end{array}$ & $1982-87$ & $\begin{array}{l}\text { Community based } \\
\text { (Greek women only) }\end{array}$ & $10(15 \cdot 1)$ & $15(22 \cdot 7)$ & $19(28 \cdot 8)$ & $5(7 \cdot 6)$ & $17(25 \cdot 8)$ & $66(100)$ \\
\hline $\begin{array}{l}\text { England }^{5} \\
\text { UK }^{9} \\
\text { Greece }^{14} \\
\text { Malaysia } \\
\text { India }^{15}\end{array}$ & $\begin{array}{l}1978-79 \\
\dagger \\
1983 \\
1990-91 \\
1988-89\end{array}$ & $\begin{array}{l}\text { Hospital based } \\
\text { Multicentre study } \\
\text { Community based } \\
\text { Community based } \\
\text { Hospital based }\end{array}$ & $\begin{array}{r}18(24 \cdot 3) \\
53(22 \cdot 7) \\
28(12 \cdot 0) \\
166(34 \cdot 4) \\
95(48 \cdot 5)\end{array}$ & $\begin{array}{c}10(13 \cdot 5) \\
51(21 \cdot 9) \\
48(20 \cdot 6) \\
66(13 \cdot 7) \\
8(4 \cdot 1)\end{array}$ & $\begin{array}{l}31(41 \cdot 9) \\
70(30 \cdot 1) \\
52(22 \cdot 3) \\
97(20 \cdot 1) \\
39(19 \cdot 9)\end{array}$ & $\begin{array}{r}12(16 \cdot 2) \\
30(12 \cdot 9) \\
93(39 \cdot 9) \\
129(26 \cdot 8) \\
47(24 \cdot 0)\end{array}$ & $\begin{array}{l}3(4 \cdot 1) \\
29(12 \cdot 4) \\
12(5 \cdot 2) \\
24(5 \cdot 0) \\
7(3 \cdot 5)\end{array}$ & $\begin{array}{r}74(100) \\
233(100) \\
233(100) \\
482(100) \\
196(100)\end{array}$ \\
\hline
\end{tabular}

^Arranged according to the Gross National Product of each country for $1991 .{ }^{18}$ 
Table 3 Comparison of cause specific mortality rates in countries using Wigglesworth pathophysiological classification

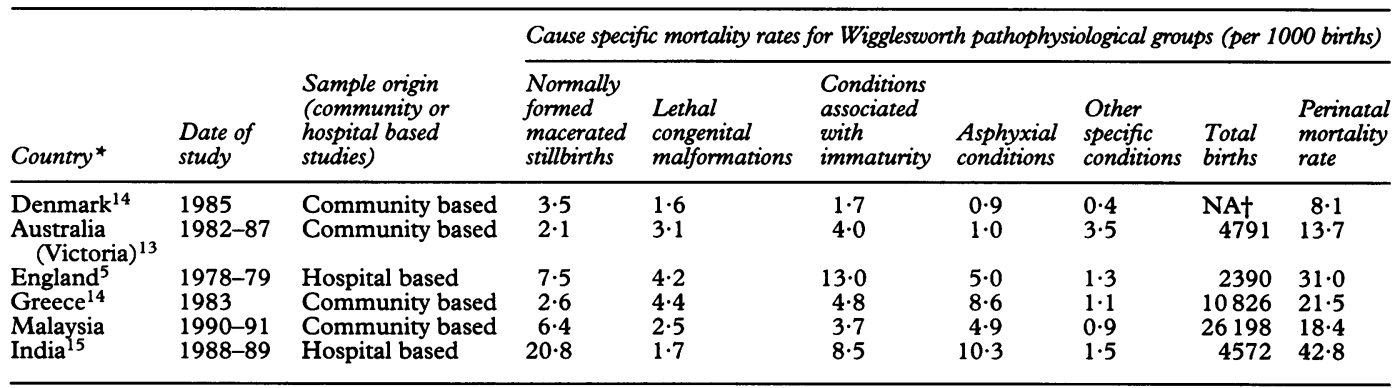

*Arranged according to the Gross National Product of each country for $1991 .{ }^{18}$

†Not available in the reference.

data on asphyxial conditions show a similar trend, decreasing in relative importance with increasing economic development, with the exception of data from Greece. These findings agree with previous opinions and studies that point to a strong correlation between perinatal deaths and socioeconomic factors. ${ }^{16} 17$

Denominators necessary to calculate birthweight specific mortality rates were not available for this study, and as such the data from this study could not be compared with those of other studies.

Another approach to compare perinatal data from different countries using Wigglesworth's pathophysiological classification is to use cause specific mortality rates. ${ }^{14}$ Cause specific mortality rates provide the perspective of perinatal deaths in relation to total number of births. They are derived by dividing the number of perinatal deaths in each Wigglesworth category by the total number of births. A comparison of cause specific mortality rates quoted in or derived from published studies ${ }^{513-15}$ is presented in table 3 . Cause specific perinatal mortality rates provide a better comparison of perinatal deaths from different studies because they take into consideration the number of births. Unfortunately, due to the factors mentioned above, such a comparison cannot be made with data from available studies. Table 3 suggests that such as comparison is a useful means of reviewing perinatal mortality data. The comparison is most accurate when national, community based data are used, because hospital based data do not accurately reflect the community situation. The value of cause specific perinatal mortality rates is greatly enhanced if they are derived by birthweight subgroups.

Cause specific mortality rates could also be used to compare perinatal mortality data among regions in the same country, especially where the socioeconomic situation of the region is similar, hence minimising the effects of these variables in the comparison. Such a comparison would more accurately reflect the quality of perinatal services provided.

As a result of this study, the Ministry of
Health is pilot testing the mechanism of using Wigglesworth classification in three states in the country. If the pilot is successful this classification will be used nation wide to monitor perinatal care and services.

This study was funded by the research and development fund of the government of Malaysia under the Intensification of Research in Priority Areas (IRPA) programme. We express our gratitude to all the study coordinators and clinicians involved from the four study regions. We thank Dr Jacqueline Ho for valuable comments made in writing this paper. We also thank the Director General of Health for permission to publish this paper.

1 Ministry of Health, Malaysia. Perinatal mortality: Overview and recommendations. Maternal \& Child Health Unit, Ministry of Health, Malaysia, 1993.

2 Kader HA. Neonatal morbidity and mortality in Peninsular Malaysia. Malaysian $\mathcal{f}$ Reprod Health 1983; 1: 139-52.

3 Kasim MS, Paramjothy M. Morbidity and mortality patterns in Malaysian children. $\mathcal{F}$ Singapore Paed Soc 1987; 29: supplement 1.

4 Siti Norazah Z, Khairuddin Y. Perinatal mortality: Selected data from a survey. Med $\mathcal{Y}$ Malaysia 1986; 41: 292-9.

5 Wigglesworth JS. Monitoring perinatal morality. A pathophysiological approach. Lancet 1980; ii: 684-6.

6 Hey EN, Lloyd DJ, Wigglesworth JS. Classifying perinatal death: fetal and neonatal factors. Br $\mathcal{f}$ Obstet Gynaecol death: fetal and neon

7 Cole SK, Hey EN, Thomson AM. Classifying perinatal death: an obstetric approach. Br $\mathcal{F}$ Obstet Gynaecol 1986; 93: 1204-12.

8 Whitfield CR, Smith NC, Cockburn F, Gibson AAM. Perinatally related wastage - a proposed classification of primary obstetric factors. Br $\mathcal{f}$ Obstet Gynaecol 1986; 93: 694-703.

9 Keeling JW, MacGillivray I, Golding J, Wigglesworth J, Berry J, Dunn PM, et al. Classification of perinatal death. Arch Dis Child 1989; 64: 1345-51.

10 Moawad AH, Lee KS, Fisher DE, Ferguson R, Phillippe $M$. A model for the prospective analysis of perinatal deaths in A model for the prospective analysis of perinatal deaths in a perinatal

11 Wong SL, Teng SC, Mohan AJ, Cheng HH, Ariffin K. A study of perinatal mortality in selected districts in Negeri Sembilan and Perak. Health Systems Research Report. Kuala Lumpur: Public Health Institute, Malaysia, 1988

12 Chiswick ML. Commentary on current World Health Organisation definitions used in perinatal statistics. Arch Dis Child 1986; 61: 708-10.

13 Lumley J, Bakoula C. Perinatal mortality in Greece and Greek-born women in Victoria. What does a 'natural experiment' suggest? Eur f Obstet Gynaecol Reproduct Biol 1993; 50: $65-70$.

14 Tzoumaka-Bakoula C, Lekea-Karanika V, Matsaniotis NS, McCarthy B, Golding J. Birthweight specific mortality in Greece. Acta Paediatr Scand 1990; 79: 47-51.

15 Raghuveer G. Perinatal deaths: relevance of Wigglesworth classification. Ped Perinatal Epidemiol 1992; 6: 45-50.

16 Macfarlane A. The derivation and use of perinatal and neonatal mortality rates. $\mathcal{F}$ Pediatr 1981 ; 98: 61-2

17 Stembera Z. Prospects for higher infant survival. World Health Forum 1990; 11: 78-83.

18 World Development Report. Cited in Introduction. In: Investing in Health. Oxford: Oxford University Press, 1993: 238-9. 